\title{
Analysis on the Current Situation of Financing of Small and Medium-sized Enterprises in Sichuan Province Under the New Development Pattern of "Dual Circulation"
}

\author{
Li Qianjin ${ }^{1, a}$, Wang Zongguang ${ }^{2, b^{*}}$
}

\author{
${ }^{1}$ Graduate Student, School of economics and management, Lanzhou University of Technology, Lanzhou, Gansu \\ Province, China \\ ${ }^{2}$ Professor, School of economics and management, Lanzhou University of Technology, Lanzhou, Gansu Province, \\ China \\ a455962433@qq.com \\ b*1966544907@qq.com
}

\begin{abstract}
As the most dynamic economic entities in China, small and medium-sized enterprises have played an important role in promoting high-quality economic development. In 2020, the Financial Stability and Development Committee of the State Council held a meeting and pointed out that the government should adhere to the principle of "two unswerving", fully realize the importance of financial support for the development of small and medium-sized enterprises, continue to increase support, and effectively alleviate the problem of difficult and expensive financing. Based on the analysis of the current situation of the financing of small and medium-sized enterprises in Sichuan Province, this paper analyzes the reasons for the financing difficulties of small and medium-sized enterprises from the internal and external financing environment, and then puts forward countermeasures and suggestions to alleviate the financing difficulties and high financing of small and medium-sized enterprises, which has certain practical significance for the development of small and medium-sized enterprises under the new development pattern of "dual circulation".
\end{abstract}

Keywords: Small and medium-sized enterprises, The financing status quo, Countermeasures and Suggestions

\section{“双循环”新发展格局下四川省中小企业融资现状探析}

\author{
李前进 ${ }^{1, a}$ 王宗光 ${ }^{2, b *}$
}

${ }^{1}$ 兰州理工大学经济管理学院研究生, 兰州, 甘肃, 中国

${ }^{2}$ 兰州理工大学经济管理学院教授, 兰州, 甘肃, 中国

a455962433@qq.com

b*1966544907@qq.com

\section{摘要}

中小企业作为我国最富有动力的微观经济主体，在推动经济高质量发展起到了重要作用。2020 年国务院金融 稳定发展委员会召开会议指出, 要坚持 “两个毫不动摇” , 充分认识到金融支持中小企业发展的重要性, 持续 加大扶持力度，切实缓解融资难融资贵的问题。本文通过对四川省中小企业融资现状分析，从融资内外部环境 分析中小企业融资难的原因, 进而提出缓解中小企业融资难融资贵的对策建议，对 “双循环” 新发展格局下中 小企业的发展具有一定的实践意义。

关键词: 中小企业, 融资现状, 对策建议 


\section{1. 引言}

中小企业一直以来都对国民经济以及社会的繁 荣发展起着不可估量的作用。尤其在吸收社会就业、 促进经济发展、增强经济韧性、促进科技创新与社会 安定发展方面, 显示出了它独特的优越性。但是随着 2020 年新冠疫情爆发, 以及国际环境的不确定因素 增加, 促使中小企业的发展也受到了一定的阻碍。中 小企业融资难的问题也一直是国内外学者关注研究 的焦点。在第十三届国际跨国公司领袖特别圆桌会议 上, 中国工业和信息化部也明确表示了培育一批链主 企业的重要性, 在 “十四五” 期间要发挥优质企业的 作用, 培养一批具备生态主导力型的产业链 “链主” 企业, 同时也要促进大小中企业的融通发展能力。《中 华人民共和国国民经济和社会发展第十四个五年规 划和 2035 年远景目标纲要》提出, 要深入实施制造 强国战略, 加强产业的基础能力建设, 推动制造业优 化升级。在此新形势下, 党中央也提出了要进一步构 建以国内大循环为主体, 国内国际双循环相互促进的 新发展格局。因此, 在中小企业抓住此机遇的同时, 也要积极打破融资难困境, 这对中小企业的自身发展 也具有战略意义。

\section{2. 四川省中小企业融资现状}

\section{1. 科技型中小企业发展速度较快}

2018 年与 2019 年, 全国中小企业数量分别达到 了 36.9 万户和 36.4 万户，2019 年与去年相比减少 了 4883 户，企业数量也在这两年呈现出了下降趋势; 2019 年四川省科技型中小企业数量为 9313 户，2020 年更是突破万户，同去年增长 $32 \%$ 。可以看出中小企 业的总体发展规模比较稳定。在四川省中小企业发展 过程中，科技型中小企业发展速度相对较快。

\section{2. 社会融资渠道多样化}

小额贷款公司试点从 2009 年开始，在各地政府 出台相关政策下，金融市场上也逐渐涌入更多的民间 资本，小额贷款公司的数量与规模也在不断地增加。
截止 2020 年 9 月, 四川省小额贷款公司数量达 237 家，注册资本金额 440.03 亿元，贷款余额为 460. 32 亿元。贷款总户数达 30.14 万户，为四川省的中小企 业发展注入了新鲜活力。整体上来看, 四川省的小额 贷款公司发展态势较好。金融行业的特殊性决定了在 经营过程中需要较高的准入门槛和相对严格的审查 与监管，因此在民间资本流动过程中，无论是从资本 总量还是从行业分布上，都带有一定的局限性。对企 业的资金支持也只能提供部分缓冲作用。因为了完善 这一问题，融资担保公司与银行合作，为中小企业的 流动资金紧缺、融资难等问题提供了较好的解决方 案。2021 年四川省融资担保数量达 102 家，其中只 有 9 家为民营企业, 其余均为国有企业。融资担保公 司可以结合政府政策, 更好地为企业融资难提供解决 思路。比如对中小企业提供 “成长贷”、“科创贷” 等。同时四川省融资担保行业也在不断增强服务中小 企业的经济力度，在中小微企业、“三农”等融资方 面也发挥了重要功能。截至到 2020 年 12 月末，四川 省融资担保户数达到了 29.76 万户，融资担保余额为 2515.20 亿元, 同比增长为 $24.91 \%$, 与银行同期的贷 款增速相比, 高出 11 个百分点, 为中小企业的发展 保驾护航。

\section{3. 社会融资规模不断增加}

社会融资规模存量是指一定时期的期末（如季 末、年末) 实体经济从金融体系获得的资金余额。从 表 1 可以看出, 2020 年社会融资规模为 284.83 万亿 元，近五年的社会融资规模存量在不断的上升，2020 年相比 2016 年增速高达 $82.6 \%$ 。委托贷款和信托贷 款也在一定程度上反映出中小企业融资贷款的经济 活动力度。（数据来源: 中国人民银行）

从四川省社会融资规模存量（表 2) 可以看出, 2020 年社会融资规模存量为 14334 亿元，2016 年为 6651 亿元，近五年的社会融资规模存量在不断的提 高, 2020 年社会融资规模存量约是 2016 年的 2.16 倍。虽然四川省的社会融资规模存量与全国相比占比 较少, 但是近五年的发展速度较快, 也在一定程度上 体现了中小企业的发展规模速度在不断地增加。（数 据来源：中国人民银行）

表 1 全国社会融资规模（万亿元）

\begin{tabular}{|c|c|c|c|c|c|}
\hline & 2020 年 & 2019 年 & 2018 年 & 2017 年 & 2016 年 \\
\hline 社会融资规模存量 & 284.83 & 251.41 & 200.75 & 174.71 & 156 \\
\hline 委托贷款额 & 11.06 & 11.44 & 12.36 & 13.97 & 13.2 \\
\hline 信托贷款额 & 6.34 & 7.45 & 7.85 & 8.53 & 6.31 \\
\hline 委托贷款和信托贷款总额 & 17.4 & 18.89 & 20.21 & 22.5 & 19.51 \\
\hline
\end{tabular}

表 2 四川省社会融资规模（亿元）

\begin{tabular}{|c|c|c|c|c|c|}
\hline & 2020 年 & 2019 年 & 2018 年 & 2017 年 & 2016 年 \\
\hline 社会融资规模存量 (亿元) & 14334 & 9653 & 8087 & 7391 & 6651 \\
\hline 委托贷款额 & -48 & -482 & -840 & 778 & 930 \\
\hline
\end{tabular}




\begin{tabular}{|c|c|c|c|c|c|}
\hline 信托贷款额 & -549 & -373 & 159 & 446 & 270 \\
\hline 委托贷款和信托贷款总额 & -597 & -855 & -681 & 1224 & 1200 \\
\hline
\end{tabular}

\section{4. 直接融资比例提升}

由于中小企业自身的特点, 注册资本金少、经营 时间周期相对较短, 资金周转弹性也是相对较小, 企 业征信相对大企业而言, 存在问题也是较多, 因此中 小企业很难通过间接投资的渠道获得资金支持。在四 川省内, 中小企业通过直接融资渠道获得资金支持也 是存在一定的难度。截止 2020 年 9 月份, 四川省 $\mathrm{A}$ 股上市公司数量达 135 家，港股上市公司数量达 27 家，上市公司的数量在全国排名中，位居第八，总市 值约为 2.7 万亿元，资产证券化率高达近 60\%。新增 上市公司的数量也呈现出了逐年提升的态势, 但是对 于企业融资而言, 也只是起到了一定的作用。新三板 也是我国资本市场的重要组成部分。截止到 2020 年 9 月 1 日, 全国在新三板挂牌企业为 8420 家。其中 四川省内已有 250 多家企业在新三板挂牌, 在全国排 名第十二位, 与经济发达的东南沿海省份还是存在着 一定的差距。

\section{3. 四川省中小企业融资难原因解析}

\section{1. 内部原因}

四川省中小企业融资难的自身原因有以下几个 方面: 一是中小企业自身的管理模式相对简单，有些 中小企业的管理方法也是相对落后，对市场预测的敏 锐度也相对较差, 对于财务监督力度也不够, 财务报 表也存在着一定的不规范性, 因此会在一定程度上造 成企业与银行之间的信息不对称。另一方面中小企业 缺乏一些贷款担保和抵押的措施。无有效资产抵押也 是中小企业融资难的原因之一。企业家景气指数与企 业家信心指数可以反映出企业家对自身企业生产经 营的判断与预期。该指数以 100 作为临界点, 当指数 高于 100 时, 表明经济运行朝较好的方向发展, 当指 数低于 100 , 则反映了经济朝不利的方向发展。通过 图表可知, 2017 年到 2020 年企业家景气指数与企业 家信心指数相对一致, 除了 2020 年第一季度外, 其 他季度相对稳定在 120 数值左右, 说明企业受新冠疫 情的影响相对较多, 但总体对企业发展规模持有乐观 态度。因此在企业不断发展扩大规模时, 也会加剧企 业对资金的需求。（数据来源：东方财富网）

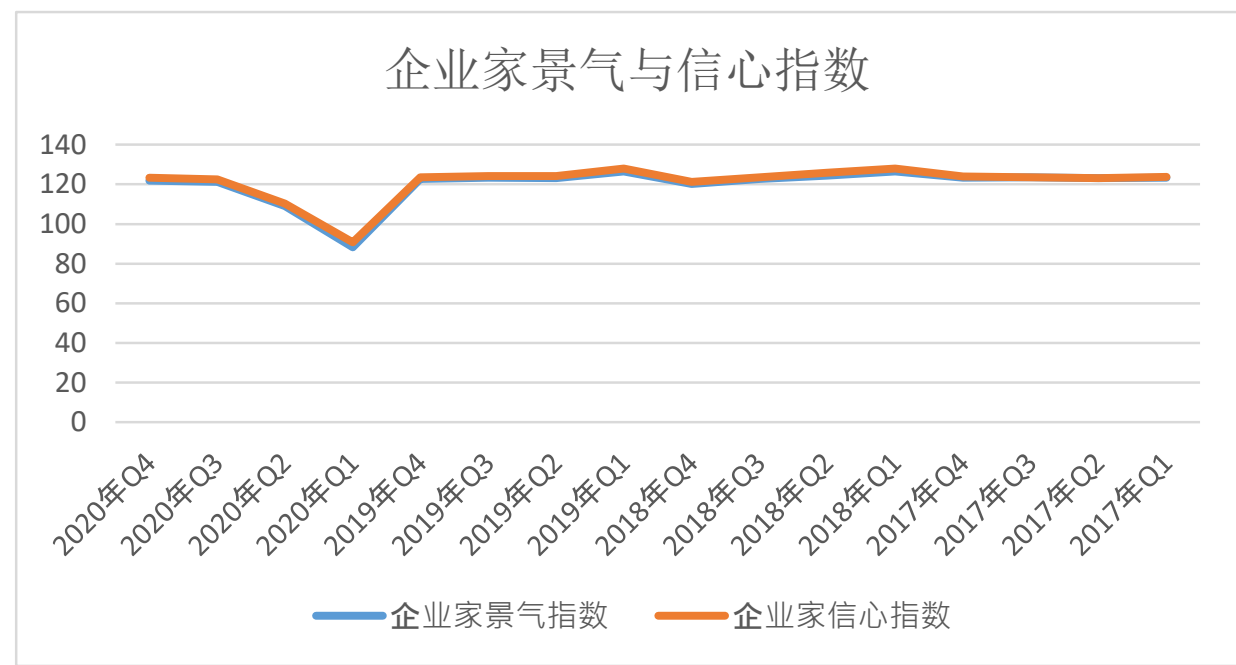

图 1 企业家景气与信心指数 $Q 1 、 Q 2 、 Q 3 、 Q 4$ 为四个季度

\section{2. 外部原因}

从当前四川省中小企业外部融资环境来看, 一是 中小企业激励约束机制方面。由于中小企业对资金需 求相比大企业而言, 相对较小, 使用的资金周转时间 也较短, 涉及的行业众多, 企业内部的风险把控意识 淡薄, 因此单户的贷款风险也较高。多数银行也没有 对中小企业的这些特点建设针对性的激励与约束机 制, 无论是银行还是担保机构, 信贷人员的风险与回 报不对称，这也导致了信贷人员对中小企业的融资贷 款更加谨慎, 挫伤信贷人员积极性。同时也出现了信 贷审批权限过于集中的问题。另一方面, 虽然四川省
政府不断出台相关文件, 对中小企业融资难提供便利 通道, 但是缺乏相应的针对性与广泛性。在金融生态 环境中，四川省的融资担保机构也起到了重要的作 用，但同时也存在着对公司审核的门槛较高、贷款金 额受限等问题。因此从四川省的信用担保体系来看的 话, 省内中小企业信用担保服务体系建设还处于发展 阶段, 虽然发展速度快、承接企业数量多、政策时效 性快, 但是也存在着缺乏规模效应、融资担保能力有 限、未与银行形成相应风险机制等问题。 


\section{4. 对策建议}

\section{1. 提高中小企业自身实力, 增强风险控制意 识}

中小企业一方面要加强自身建设, 积极参与企业 创新，规范自身财务管理，在产品更新换代的同时， 也要深掘市场需求, 促进自身经济实力发展, 为企业 内部融资奠定良好的基础。中小企业在提高自身硬实 力的同时, 也要注重文化软实力, 建立健全内部法规 条例, 严格完善财务管理、职责分离、内部审计等制 度。另一方面, 也要在公司内部增强企业的风险控制 意识, 提高企业的品牌知名度, 增强企业的自身影响 力, 信用是企业的无形资产, 企业要提高自身的公信 度, 维持良好的信用等级体系, 这样更有利于拓宽企 业的融资渠道, 为企业的发展奠定基础。

\section{2. 利用国际国内双循环优势, 深耕市场潜力}

现阶段由于外部环境的复杂性, 疫情的持续蔓延 以及国际关系的不确定性, 中小企业更应该利用国内 国外经济循环的畅通, 促进国内市场的稳定发展, 加 速产业循环和市场循环以及经济循环的良性互动, 同 时企业也要推动自身的产业升级, 向 “专、精、深、 特、新” 方向发展。深耕市场潜力, 提高自身经营能 力, 推动产业链向微笑曲线两端不断延申, 提高企业 的经济发展潜力。同时也要深入国内市场, 不断地增 强自身的企业实力, 加强供货商的联系, 提高企业的 采购能力。另一方面, 也要进一步提高直接融资的比 例, 丰富自身的融资渠道。只有充分的利用 “双循环” 经济, 才能不断地为企业增添活力。

\section{3. 出台相关优惠政策, 营造良好信贷环境}

2021 年国务院促进中小企业发展工作领导小组 会议指出, “着力缓解中小企业融资难、融资贵”。 中小企业在市场经济、居民就业等方面都起到了至关 重要的作用, 也是提升整个产业链和供应链稳定的中 心环节, 也为整个社会的发展贡献了独特力量。2020 年, 中小企业因新冠疫情的影响, 流动资金与日常生 产经营都受到了一定的影响。但是各地政府部门也都 出台了多项金融措施，对中小企业的信贷融资也开辟 了绿色通道，根据数据显示， 2020 年银行业对 7.3 万亿元的贷款延期还本付息。四川省也要继续积极搭 建促进中小企业融通发展平台, 在中小企业的融资贷 款、科技成果转化以及税收优惠方面也要继续出台相 关政策，更好的为企业的发展保驾护航。

\section{4. 利用互联网技术，提高企业经济韧性}

近几年, 国家数字经济创新发展试验区启动建 设, 四川省作为其中的试验区之一, 也要进一步的通 过与数字经济的融合, 将传统行业的升级转型创造条 件, 同时也要进一步发挥互联网金融的作用, 通过方
式方法的创新，对企业贷款、放款等程序进行快速化 处理，将办理程序与互联网技术有机结合起来，更好 的为中小企业服务, 同时也是建造数字经济的一部 分，为企业融资筹资降低成本，拓宽企业融资渠道， 让企业的发展与互联网数字经济紧密结合起来。

\section{5. 结论}

本文通过科技型中小企业发展速度、社会融资渠 道、社会融资规模、中小企业直接融资概况四个方面 对四川省中小企业融资的现状进行了简要阐述。同时 针对四川省中小企业的内外部融资环境问题，提出相 应的对策与建议: 中小企业要进一步提高自身实力, 增强风险把控意识，在 “双循环” 新格局下积极深耕 市场需求。政府也要出台相关优惠政策，构建数字经 济，为企业融资营造良好的信贷环境。

\section{REFERENCES}

[1] Jiang, Z.L.(2021)The choice of monetary policy in solving the financing problems of SMEs and macroeconomic stability. Studies of International Finance.,(04):23-32.

[2] Ji,J.(2021)Research on the countermeasures of difficulties in financing for SMEs--take Longhua district of Shenzhen as an example. Special Zone Economy.,(03):122-124.

[3] Yuan, Z.G., Guo, X.Q., Ge,J.F.(2021)SME financing and the development of small and medium-sized banks -- theoretical and empirical analysis caused by China's practical problems. Shanghai Journal of Economics., (05):51-52+54.

[4] Ren, C.R.(2021)Suggestions on improving the ability of "double circulation" of financial services through the linkage of investment and loan.China Logistics \& Purchasing.,(01):53.

[5] Zhao, L.L., Liu,C.J.,Zhao,D.(2020)Discussion on financing and innovation development of SMEs in science and technology. High Technology and Industrialization., 26(12):70-74.

[6] Wang,J.F.(2020)Research on financing innovation path of small and medium-sized enterprises in Qinghai high-tech zone.Modern business.,(36):146-148.

[7] Li, D.S.,Xia,R.P.,Yang,J.(2021)Government-enterprise relationship, financing constraints and SMEs' R\&D innovation: Based on data from the World Bank's China Business Environment Survey. Hainan finance.,(03):15-23.

[8] Liu, S.H.,Yu,M.,Liu,Y.S.(2021)Research on solutions to financing problems of small and medium-sized enterprises from the perspective of technological financial innovation -- a case study of Baoding City, Hebei Province. Technology and Economic Guide., (04):190-192. 